\title{
STUDY ON THE SPATIAL EXPANSION OF GARDEN CITY UNDER THE ECOLOGICAL GREEN SPACES PROTECTION (QUJING AREA, CHINA)
}

\author{
ZHANG, H. N. ${ }^{1,2}-$ WEN, X. P. ${ }^{1,2^{*}}-$ XU, J. L. ${ }^{1,2}-$ LUO, D. Y. ${ }^{1,2}-$ LI, J. B. ${ }^{1,2}$ \\ ${ }^{I}$ Faculty of Land Resource Engineering, Kunming University of Science and Technology \\ Kunming 650093, China \\ (phone: +86-871-6515-3408) \\ ${ }^{2}$ Mineral Resources Prediction and Evaluation Engineering Laboratory of Yunnan Province \\ Kunming 650093, China \\ (phone: +86-871-6518-6335) \\ *Corresponding author \\ e-mail:wfxyp@qq.com; phone: +86-150-2514-8278 \\ (Received $2^{\text {nd }}$ Apr 2018; accepted $29^{\text {th }}$ Jun 2018)
}

\begin{abstract}
With the acceleration of urbanization in China, the phenomenon of occupying ecological green space is becoming more serious in the process of urbanization, especially in Chinese Nationally Designated Garden Cities. The study simulates the dynamic change of Qujing in Yunnan Province of the 1993-2015 period. According to different ecological green space protection intensity, four kinds of scenarios were set up to predict the urban expansion in 2030. The spatial and temporal characteristics of urban expansion under different scenarios are quantitatively studied by using the Urban Expansion Intensity Index (UEII) and Urban Expansion Speed Index (UESI). The results show that the SLEUTH model has strong applicability and can better reflect the spatial and temporal characteristics of the urban expansion in Garden City. In four scenarios, the urban area shows an increasing trend, and the urban expansion speed and urban expansion intensity decrease with the increase of ecological protection intensity. Comparing four scenarios, we found that the urban development trend predicted by the ecological development scenario is more similar to the urban planning, and this conclusion has been confirmed by the distribution of urban areas of 2018. In ecological development scenario, the urban ecological land has been effectively protected and the development of the city has not been affected, which is beneficial to the sustainable development and the protection of the ecological environment. For urban planning, the suitable measures of ecological green space protection can restrain the urban expansion, and the ecological protection-oriented development mode accords with the development trend of Garden City.
\end{abstract}

Keywords: ecological green space, urban expansion, SLEUTH model, dynamic change, sustainable development

\section{Introduction}

Urban expansion is the inevitable result of social and economic development (Hansen et al., 2005). With the acceleration of urbanization in China, a large number of ecological green spaces were occupied in the process of urban construction. This phenomenon is more prominent in Chinese Nationally Designated Garden Cities, leading to a large number of urbanization problems, such as heat island effect, city haze, soil erosion and so on (Black, 1999; Peck, 2005). Most urban development researches attach importance to the solution of two problems: one is about ensuring the sustainable development of cities, another concerns minimizing the impact on ecological environment during urban expansion (López et al., 2001; Roberts and Diederichs, 2016; Boulos, 2016). 
In recent years, many researchers have established a large number of models to simulate and predict the spatial expansion of cities. On the basis of two experiments conducted in San Francisco and the Washington area, Clarke (1997) and Silva (2002) pointed out that with its high accuracy, the SLEUTH model not only can be used to simulate urban evolution by making use of historical data, but also can be applied to predicting urban expansion from a macro perspective and a meso perspective (Silva and Clark, 2005). Pijanowski (2002) used the Land Transformation Model (LTM) to explore the consequences of future urban changes of 2020 and 2040 with the help of non-urban sprawl and urban-sprawl trends. Results of this work have significant implications for the Lake Michigan Lake Area Management Plan developed by the United States Environmental Protection Agency recently. But the model did not embody the influences of terrain and policy on the urban expansion. The Cellular Automata (CA) model can be used to simulate different urban forms and developments in the planning of sustainable cities (Yeh et al., 2001). However, due to the fact that the conversion rules of cell can not be quantified in practical application, the accuracy of model simulation is low. Yea explored the simulation of urban growth by applying SLEUTH model to Yilan, Luodong and Suao in the Yilan Delta area of northeast Taiwan, so that he can make use of some historical data and study the dynamics of the region. He found that the result of the model's application for predicting city development in the Yilan Delta area shows that the cities of Yilan and Luodong are developing and expanding more evenly from the city center (Yea and Yang, 2007). It is found that when CA model is applied to simulating the dynamic evolution of complex urban expansion, the transformation rules and parameters of the model are difficult to design quantitatively and it is difficult to explain the physical meaning of the model parameters.

SLEUTH model can simulate and forecast urban expansion based on cellular automata. It can predict the possibility of urban expansion according to traffic, topography and urban development constrains because pixels of the current city fucntion as seed points to present the future development of the city through their diffusion (Herold et al., 2003; Xian and Crane, 2005; Silva and Clark, 2005). Compared with the traditional CA model, the most important feature of SLEUTH model is the optimal parameter combination for urban expansion process calculated by Monte Carlo iterative simulation. Because of its high simulation precision, easy access and portability, the model has been widely used in the study of urban expansion simulation and prediction (Dietzel and Clarke, 2004). At present, the SLEUTH model is often used in dynamic simulation studies of large cities. However, there are few researches on Garden Cities with higher greening coverage (Laura et al., 2008; Dietzel and Clarke, 2007; Mc and Justin, 2013). Based on the existing theory of urban expansion and the application of SLEUTH model, this paper takes the Nationally Designated Garden Cities (Qujing) as the research area. According to the actual situation of the research area, four kinds of scenarios are set up based on the protection intensity of different ecological green space, and the spatial expansion of the city is simulated and forecasted. The spatial and temporal characteristics of urban sprawl in different scenarios are quantitatively studied by using the Urban Expansion Intensity Index (UEII) and Urban Expansion Speed Index (UESI). Comparing four scenarios with urban planning of 2030, the most similar scenario with urban development trends was identified, and the conclusion was confirmed by the distribution of urban areas of 2018. Basic laws and trends of urban spatial expansion in the research area are revealed, which provide 
references for the sustainable development and urban planning of Nationally Designated Garden Cities in China.

\section{Materials and methods}

\section{Study area}

Qujing, located in the eastern part of Yunnan Province, China, is an important industrial and commercial city and transportation hub in Yunnan province. It is adjacent to Guizhou province and Guangxi Zhuang Autonomous Region. With the rapid urbanization construction, the whole city has been increased from $81.27 \mathrm{~km}^{2}$ in 1997 to $253.8 \mathrm{~km}^{2}$ in 2016, but its urban green space area has also reduced (Ding, 2010). Located in the low latitude area, Qujing has a subtropical plateau type monsoon climate. The annual average temperature is $14.5^{\circ} \mathrm{C}$, and the annual rainfall at the urban area is over $1,008 \mathrm{~mm}$. The difference between summer temperature and winter temperature in most areas is small, which means the climate is very mild and suitable for human habitation. The average forest coverage is about $45 \%$, and the urban green coverage is $36.16 \%$, it is a typical Nationally Designated Garden City in the west of China. In this paper, the study area is the central area of Qujing, which covers the northern Qiling District and southern Zhanyi District. The research area lies between longitude $103^{\circ} 42^{\prime} 18^{\prime \prime}$ to $103^{\circ} 54^{\prime} 54^{\prime \prime}$ east and latitude $25^{\circ} 24^{\prime} 18^{\prime \prime}$ to $25^{\circ} 38^{\prime} 24^{\prime \prime}$ north, the total area is about $1061.9 \mathrm{~km}^{2}$ (Yuan et al., 2017). The research area locates in the plain area; the terrain is low in the middle: the middle is flat dam area, the east-west side is mountainous. The spatial pattern shows the area's transition from the city core to the suburb (Fig. 1).

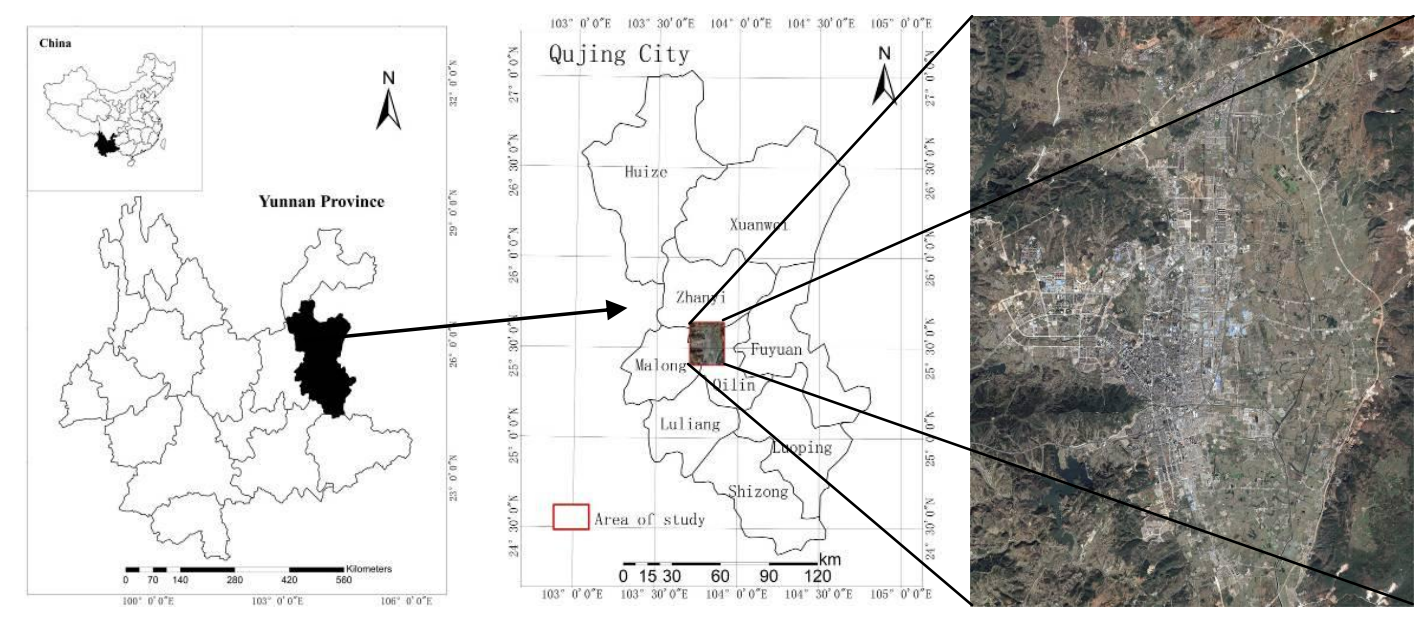

Figure 1. Location map and high-resolution image of the research area. (Image photos from Google Earth in September 2017)

\section{Data acquisition and preprocessing}

The basic data of the study area were gathered from 1993 Landsat TM images, 2000 Landsat ETM images, 2009 Landsat TM images and the Landsat OLI images in 2015 and 2018 (Fig. 2), which were collected in September to December. The cloud cover was less than 5\% and they can be used for visual interpretation (Morf, 2011). In 
addition, the data of digital elevation model (DEM) for 2015 in the research area, the urban road traffic map of the corresponding year and the urban planning map of the research area were collected. The classification of remote sensing images was based on supervised classification method, through which researchers classified the images in accordance with six land use types including urban land, bare land, farmland, forestland, grassland and waters. Then we used the Government Gazette of Qujing and the data of field survey to test the precision of classification results. The total precision data of the classification resulting in four periods were $83.17 \%, 86.52 \%, 85.45 \%$ and $87.89 \%$ respectively. Additionally, the kappa coefficients of these periods were higher than 0.79 , which can meet the needs of this paper. According to the operational requirements of the SLEUTH model, the traffic road layer, slope layer, shadow layer, city range layer and exclusion layer were made by ArcGIS (Rafiee et al., 2009; Feng et al., 2008).

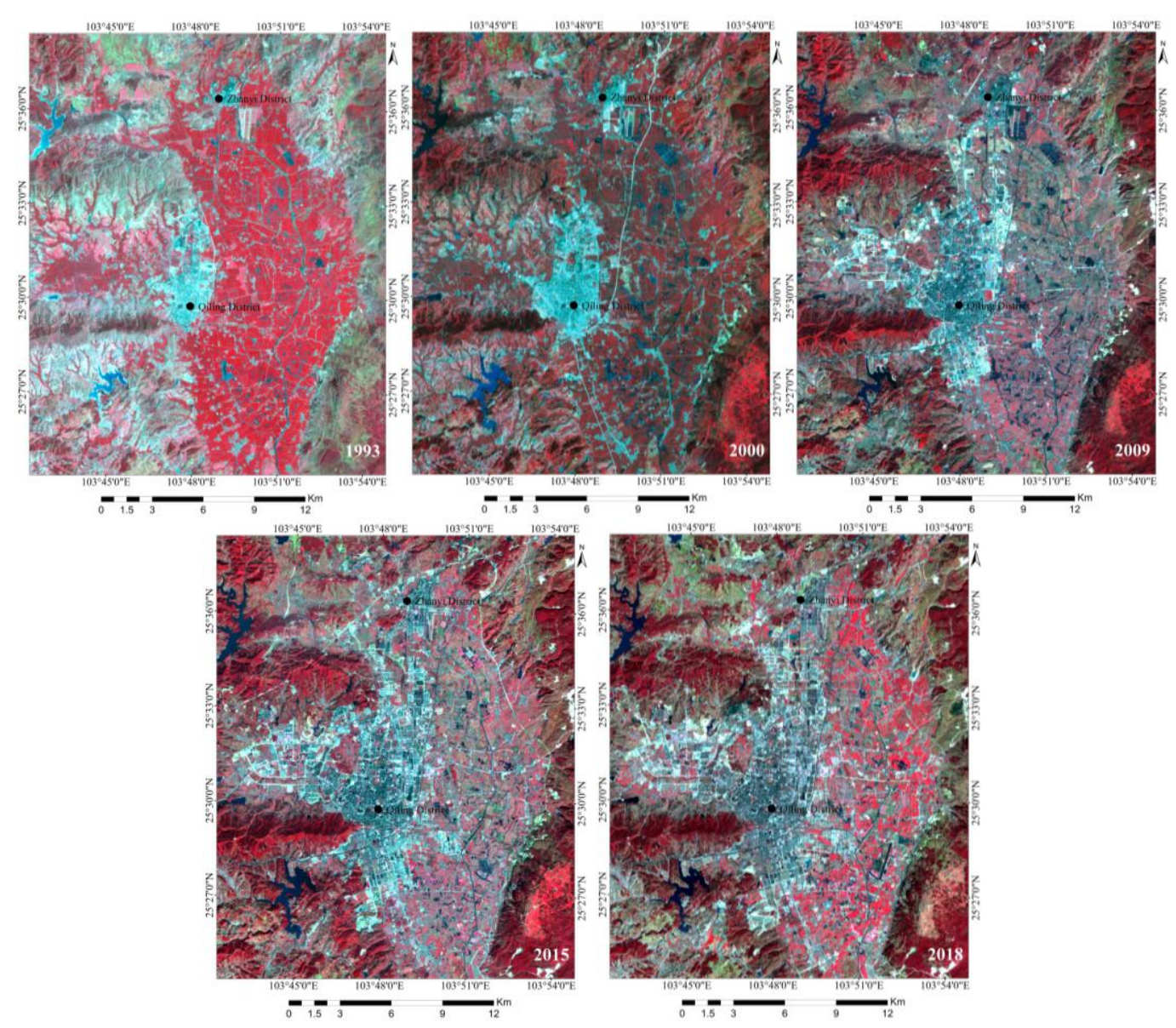

Figure 2. Remote sensing images from 1993 (Landsat 5), 2000 (Landsat 7), 2009 (Landsat 5), 2015 (Landsat 8) and 2018 (Landsat 8) in the central areas of Qujing. (The false color composite of Landsat5 (RGB)432, Landsat7 (RGB)432 and Landsat8 (RGB)543)

Based on the urban road traffic map of the year, the layer of the traffic road was created by digital processing. According to the classification of road grade, they were given different weights, among which the main urban road was given a weight value of 100 , the urban secondary road was given a weight value of 50, and the non-road 
assignment is 0 . Researchers collected the urban range vector data through the supervision of the classification of the years and then convert them to different spatial resolution grids with the use of the ArcGIS Toolbox and the classification of the generation of research areas of the city map. Upon finishing this work, the urban layer was created in the fourth period of remote sensing image prepossessing. The slope layer was generated by the re-projection and re-sampling of DEM data, which was expressed as a percentage slope value. The shadow layer was the background of the model image output which improves the spatial visual effect of the simulated urban spatial expansion process. The shadow layer was embedded as a background layer and was not involved in the operation of the model. The exclusion layer, whose range is $0-100$, was a constrained layer that restricted the simulated expansion of the urban area. When this value tends to be 0 , the probability of urbanization is higher, and when this value tends to be 100 , the probability of urbanization is lower. All of the input layers were converted to 8-bit grayscale raster images projected by horizontal Mercator (UTM_WGS1984 48N), and the data format was required to be in GIF format.

\section{SLEUTH model and the setting of multiple scenarios}

The SLEUTH model was developed by Professor Clark of the University of California. The model is capable of predicting the dynamics of urban growth. The basic urban growth procedure of SLEUTH is a cellular automaton, in which urban expansion is modeled in a GIS environment (Chaudhuri and Clarke, 2014; AlShalabi, 2013). The major characteristic of the model is that the computer can automatically judge the coincidence degree between the simulation result and the actual situation. It can find the combination scheme with the least error, and works out the best parameter combination. The model assumes that the future phenomenon could be simulated by the past real evolution trend, while assuming that the historical growth trend is sustained. The model can simulate and predict urban dynamics through the application of four growth rules: spontaneous growth, new expansion centers, marginal growth, and Road-Influenced, which are controlled by five parameters: diffusion, breed, spread, slope and road gravity (Silva and Clarke, 2002). In order to enable the simulation result to be more accordant with the real situation, the model can adjust the growth coefficient through the selfadjusting function (Sangawongse et al., 2005). By altering the self-organization constraints or changing parameter values that affect the expansion of the urban area, scenarios for different planning goals can be transplanted into the SLEUTH model, and patterns of future urban area differing in quantity and location may be generated (Solecki et al., 2004; Feng et al., 2008; Liu and Ying, 2012). SLEUTH model has now been updated to the 3.0 beta version, and it is available on the United States Geological Survey website. The new version SLEUTH model can better simulate the historical trend of urban growth and improve the calibration efficiency of the model compared to the previous version in the calibration module (Watkiss, 2008). The city simulation module of the model was applied to this investigation and was debugged and compiled by using Cygwin software in the Windows system before running.

The SLEUTH model cannot reflect the influence of government decision and social economy on urban expansion, for this reason different scenarios are often introduced to simulate the future growth of the city (Xiang and Clarke, 2003; Feng et al., 2012; Dezhkamet al., 2014). When setting up the forecast scenarios, the future of urban planning and the actual situation were taken into consideration. According to "The Urban Master Planning of Qujing from the Year 2016 to 2030" (CAUPD and QCPB, 
2016), the eastern region will be protected in the course of future urbanization, because of the plenty of protected ecological land in that region. According to the existing research results and the actual situation of the research area, four scenarios were determined and assigned to the local classes in this investigation, and the specific assignment is shown in Table 1. In general, the existing cities appeared in the exclusion layer were assigned 0 , some of the lakes and waters were assigned 100, while woodland, arable land, bare land, and grassland were assigned a value of 0-100 according to the study. We mostly assigned greater value to the ground classes that need to be protected, so that these areas are less likely to be urbanized, and the protected areas designed in this investigation are based on urban planning (Jantz et al., 2004). In the scenarios of natural development, it was assumed that the future expansion of urban space would be based on the existing urban space, and urban spatial expansion is not affected by planning, policy, ecological environment and so on, only assigning 100 to waters. In the planning-oriented scenario, it was assumed that the future cities would took the construction of urbanization as the dominant factor, some farmland, grassland and the forest land may be urbanized. In the ecological development scenario, it was assumed that the future city would be in the protection of the existing urban ecological pattern on the basis of expansion, so as to avoid the land occupancy and protect the cultivated land during urbanization. In the scenario of ecological protection, by increasing the protection of ecological green space and reducing the speed of urbanization in the future, the waters, forestland and key protected areas in the research area were designed as being forbidden to be urbanized, and the protection level of bare land, farmland and grassland were designed to be higher correspondingly (Fig. 3).

Table 1. Excluded assignments of scenarios 1-4

\begin{tabular}{c|c|c|c|c|c|c|c}
\hline Scenario settings & $\begin{array}{c}\text { Urban land } \\
\text { in 2015 }\end{array}$ & Waters & $\begin{array}{c}\text { Bare } \\
\text { land }\end{array}$ & $\begin{array}{c}\text { Farm } \\
\text { land }\end{array}$ & Grassland & $\begin{array}{c}\text { Forest } \\
\text { land }\end{array}$ & $\begin{array}{c}\text { Protected } \\
\text { land }\end{array}$ \\
\hline $\begin{array}{c}\text { Scenario 1 } \\
\text { (Natural development) }\end{array}$ & 0 & 100 & 0 & 0 & 0 & 0 & - \\
$\begin{array}{c}\text { Scenario 2 } \\
\text { (Planning-oriented) }\end{array}$ & 0 & 100 & 0 & 25 & 25 & 50 & - \\
$\begin{array}{c}\text { Scenario 3 } \\
\text { (Ecological development) }\end{array}$ & 0 & 100 & 50 & 25 & 25 & 100 & 100 \\
$\begin{array}{c}\text { Scenario 4 } \\
\text { (Ecological protection) }\end{array}$ & 0 & 100 & 50 & 50 & 50 & 100 & 100 \\
\hline
\end{tabular}

\section{Spatial-temporal analysis indicators of urban expansion}

Urban Expansion Speed Index (UESI) and Urban Expansion Intensity Index (UEII) are the common indices for the study of urban expansion quantitative characteristics. They are used to characterize the speed and degree of urban expansion (Al-Sharif et al., 2014; Wang et al., 2016). These two indexes simply describe and analyse the change of material space from the result of urban expansion by comparing the speed and strength of urban expansion in different periods, studying the characteristics of the change of urban expansion form, and revealing the spatial and morphological evolution law of urban expansion (Terry, 1995; Salvati et al., 2014). In order to explore the temporal and spatial patterns of urban land use growth in Qujing, the two analytical indices are introduced in this paper. 


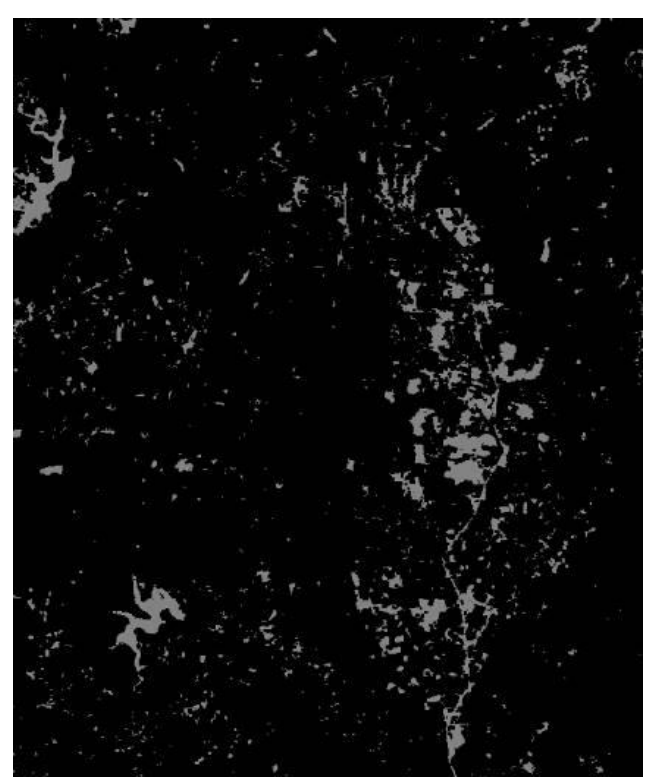

a

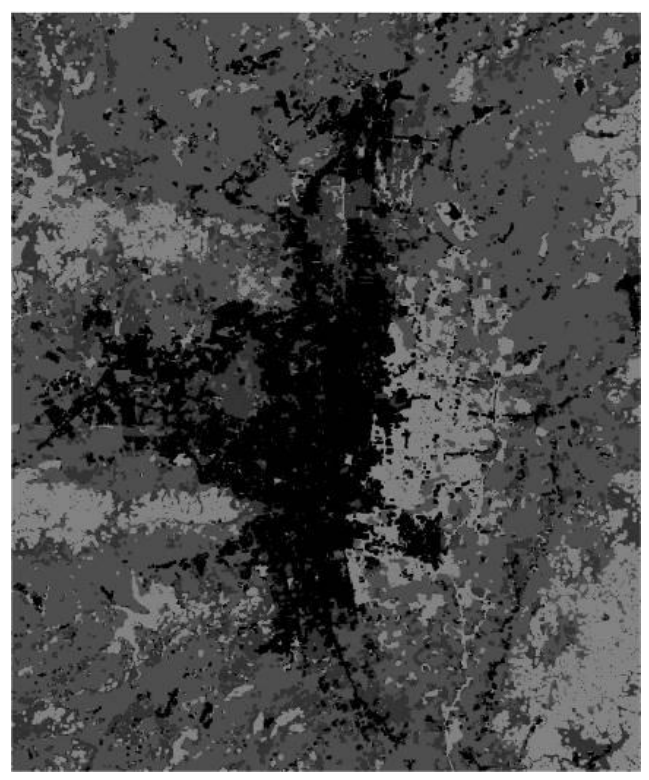

c

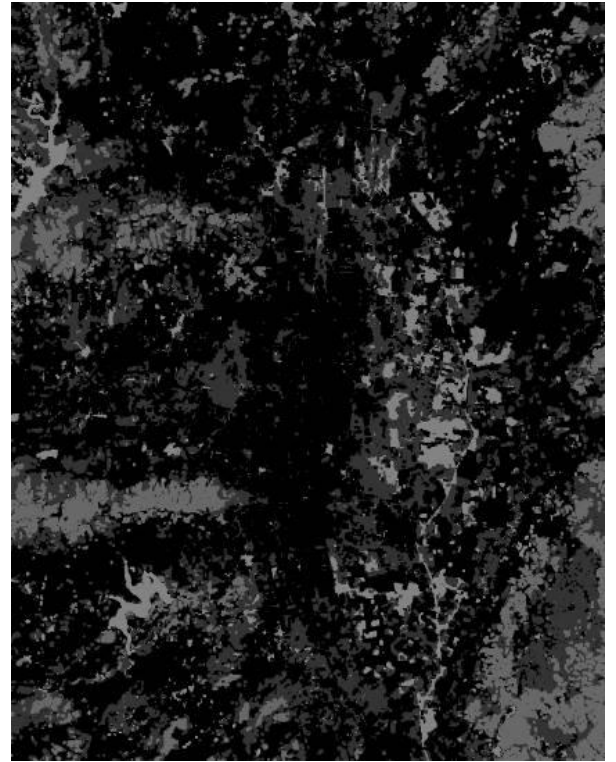

b

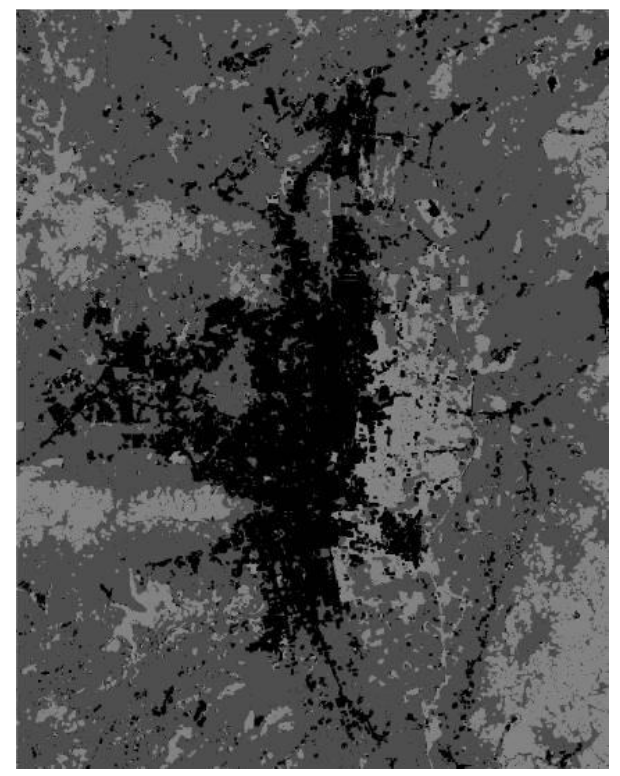

d

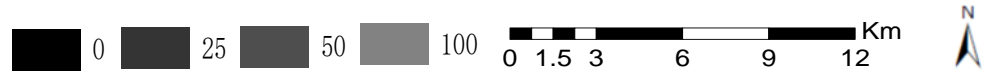

Figure 3. The exclusion layer of scenario 1-4. a Scenario 1, b scenario 2, $\boldsymbol{c}$ scenario 3, $\boldsymbol{d}$ scenario 4

\section{(1) Urban expansion speed index}

The UESI indicates the range of urban land area change at a certain time, which can reflect the overall scale and trend of urban expansion, and the formula is shown as follows (Eq. I):

$$
U E S I=\frac{\left(U A_{n+i}-U A_{\mathrm{i}}\right)}{n}
$$




\section{(2) Urban expansion intensity index}

The UEII is used to reflect the percentage of the total urban land area in a certain period. If the index increases, it means that the urban area expands at a faster rate in this period. The formula is shown as follows (Eq. 2):

$$
U E I I=\frac{\left(U A_{n+i}-U A_{\mathrm{i}}\right)}{U A_{\mathrm{i}}}
$$

In the above formula: UESI represents the expansion rate of urban land use, UEII represents the expansion intensity of urban land use. $U A_{n+i}, U A_{i}$ is the $n+i$ year and $i$ year urban area, $\mathrm{n}$ represents the time interval in years.

\section{Results and discussion}

\section{The correction result of SLEUTH model and validation of the simulation results}

In general, the Compare Index and Lee-Sallee Index were often used to evaluate the precision of the simulation results (Clarke et al., 1997; Silva and Clarke, 2002). In this experiment, the Compare Index is 0.83 and Lee-sallee Index is 0.67 , which indicate that the total number of urbanized pixels and urban boundary in the simulated year coincide with the actual situation. In the previous study, the Compare Index can generally reach more than $85 \%$, Lee-sallee Index is generally from 0.3 to 0.7 . But to some cities in the western part of China, these two indices may be less affected by topography and ecological environment (Herold et al., 2003; Mc and Justin, 2013; Zhao et al., 2014). The calibration process and parameters are shown in Table 2. The optimal parameter combination was obtained by final correction, and the walking coefficient and propagation coefficient were 15 and 18 , which indicated that the effect of the study area on the urban development was small. The diffusion coefficient was 86 , which indicated that the urban expansion was autonomous by marginal growth. The slope coefficient was 20 while the road coefficient was 72 . It is indicated that the slope has limited restriction in the process of urban expansion. On the contrary, the increasing effect of road gravity is obvious, which is consistent with the results of other applications in China (Yuan et al., 2011; Feng et al., 2012; Zhao et al., 2014).

Table 2. The correction result of SLEUTH model

\begin{tabular}{c|c|c|c|c|c|c|c}
\hline \multirow{2}{*}{ Growth factors } & \multicolumn{2}{|c|}{ Rough correction } & \multicolumn{2}{c|}{$\begin{array}{c}\text { Accurate } \\
\text { correction }\end{array}$} & \multicolumn{2}{c|}{ Final correction } & $\begin{array}{c}\text { Final reference } \\
\text { value }\end{array}$ \\
\hline \multirow{2}{*}{ Monte Carlo iteration } & \multicolumn{2}{|c|}{10} & \multicolumn{2}{|c|}{20} & \multicolumn{2}{|c|}{30} & \\
\cline { 2 - 7 } & Range & Step & Range & Step & Range & Step & \\
\cline { 2 - 7 } Diffusion coefficient & $1-100$ & 25 & $0-50$ & 10 & $10-20$ & 1 & 15 \\
Breed coefficient & $1-100$ & 25 & $0-50$ & 10 & $0-25$ & 2 & 18 \\
Spread coefficient & $1-100$ & 25 & $50-100$ & 10 & $80-90$ & 1 & 86 \\
Slope coefficient & $1-100$ & 25 & $0-50$ & 10 & $10-25$ & 1 & 20 \\
Road coefficient & $1-100$ & 25 & $50-100$ & 10 & $70-85$ & 1 & 72 \\
\hline Compare Index & \multicolumn{2}{|c|}{0.75} & \multicolumn{2}{c|}{0.79} & 0.83 & \\
Lee-Sallee Index & \multicolumn{2}{|c|}{0.55} & \multicolumn{2}{c|}{0.61} & 0.67 & \\
\hline
\end{tabular}


In order to verify the simulation results of the SLEUTH model, we simulated the urban expansion process from 1993 to 2015 with the parameters obtained from the final correction. The data of simulation results and the real situation were gathered in 2000 , 2009, and 2015 (the starting year is 1993, so the data of 1993 are not included in Fig. 4 and Table 3).

Table 3. Comparison between simulation results and actual situation

\begin{tabular}{|c|c|c|c|}
\hline Year & 2000 & 2009 & 2015 \\
\hline Number of urban pixels in the actual situation /unit & 13741 & 19802 & 24098 \\
\hline Number of urban pixels in the simulated result /unit & 16021 & 23870 & 31976 \\
\hline Precision of simulation $1 \%$ & 85.77 & 82.96 & 75.36 \\
\hline
\end{tabular}
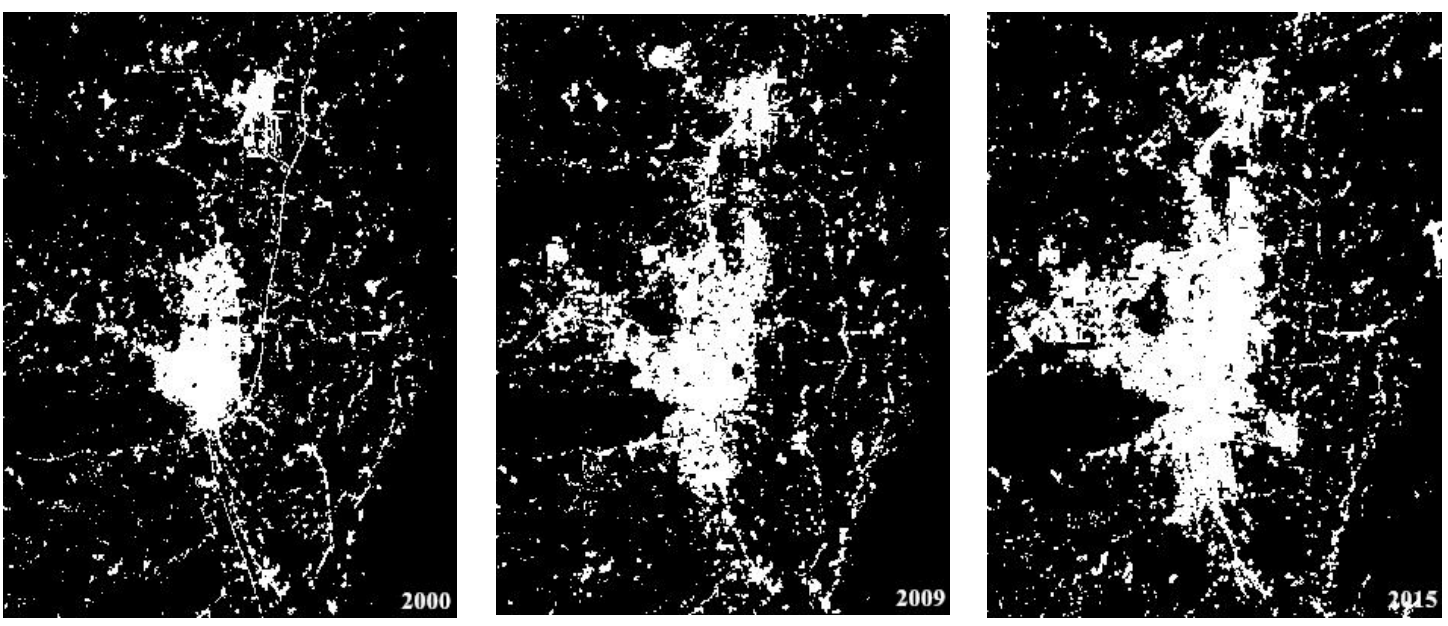

Urban areas

Non-urban areas

$\begin{array}{llllll}0 & 1.5 & 3 & 6 & 9 & 12\end{array}$

a
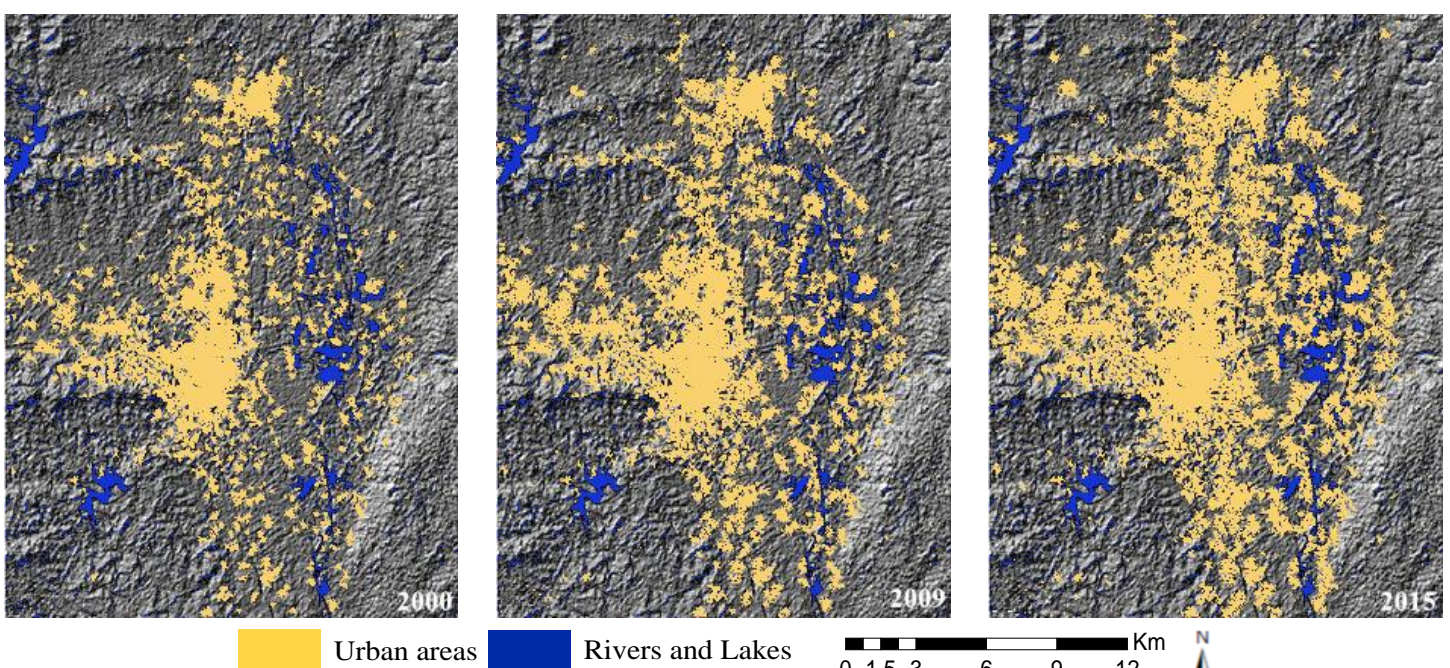

Rivers and Lakes

01.53

b

Figure 4. Comparison of simulation results of SLEUTH model with actual situation in Qujing city. $\boldsymbol{a}$ The actual situation and $\boldsymbol{b}$ the simulated results of Qujing city in 2000, 2009 and 2015 
As can be seen from Figure 4, the simulation results are similar to the actual spatial distribution: the simulated urban areas mainly extend along the road, and the old town is centered around Qujing, which accords with the characteristics of the development along the road and the edge growth. However, the difference between the two is very prominent, because the government prohibits the occupation of the large amount of ecological land in the eastern region, and as a result the expansion of the city in the eastern region is limited. However, in the simulation of urban settlements, a large scale of expansion also appeared in the eastern part, which is mainly caused by the high spread coefficient (Mc et al., 2013; Rafiee et al., 2009). The result of the simulation can not fully reflect the transfer of urban development center caused by the change of government behavior, because the cell is very dependent on the neighboring state, which is easy to expand outwards on the basis of the existing city, and the new diffusion center is not easy to appear (Salvati et al., 2014; Liu et al., 2010; Chaudhuri and Clarke, 2014).

We not only used the Compare Index and Lee-scale Index to evaluate the accuracy of simulation results, but also compared the actual situation with simulation results. Additionally, data about the number of pixel points and the precision of simulation are collected (Table 3). It can be seen that the precision is higher than $75 \%$ in three periods, which indicates that the simulation results are in accordance with the actual situation. The precision of simulation is $85.77 \%, 82.96$ and $75.36 \%$ in 2000, 2009 and 2015 respectively. With the increase of the simulated year, the precision decreases gradually, while similar situations have occurred in other studies (Clarke and Gaydos, 1998; Liu et al., 2010). This is mainly due to the shift of the city center during the expansion, which was not taken into account in the process of urban simulation (Aerts et al., 2009). Therefore, it is necessary to integrate urban planning factor into urban expansion data. The exclusion layer of sleuth model in urban expansion forecast can solve this problem effectively.

\section{The prediction results of the urban expansion}

The reference value of each coefficient is observed in the final correction. 100 times Monte Carlo iteration is used to predict the urban spatial expansion while the 2016 to 2030 forecast years were designed. The results are shown in Figure 5 and Table 4.

Table 4. The prediction results of scenario 1-4

\begin{tabular}{c|c|c|c|c}
\hline Urban area & Scenario 1 & Scenario 2 & Scenario 3 & Scenario 4 \\
\hline Current urban area (yellow) $/ \mathrm{km}^{2}$ & 213.27 & 213.27 & 213.27 & 213.27 \\
Urbanization rate $70-100 \%(\mathrm{red}) / \mathrm{km}^{2}$ & 105.98 & 74.86 & 51.48 & 20.21 \\
Urbanization rate $40-70 \%$ (green) $/ \mathrm{km}^{2}$ & 19.65 & 20.60 & 21.37 & 19.12 \\
Urban area in 2030/km & 338.9 & 308.73 & 286.12 & 252.6 \\
\hline
\end{tabular}

From Figure $5 a$ it can be seen that in the natural development scenario, the development of the city is almost free from any restrictions. Cities occupy a large amount of ecological green space in the process of expansion, which is more prominent in the suburbs of the eastern part of the city. In this scenario, the urban land area would be a total of $125.63 \mathrm{~km}^{2}$ in 2030 with an average annual growth rate of $3.93 \%$. Besides, 
a large number of urbanized pixels can be seen from the eastern part of the study area, which means the probability of urbanization ranging from $70 \%$ to $100 \%$ by 2030 . Most of the newly added urban land was originally the outskirts of the city, which led to the fragmentation of the spatial pattern and aggravate the contradiction between urban development and ecological protection.

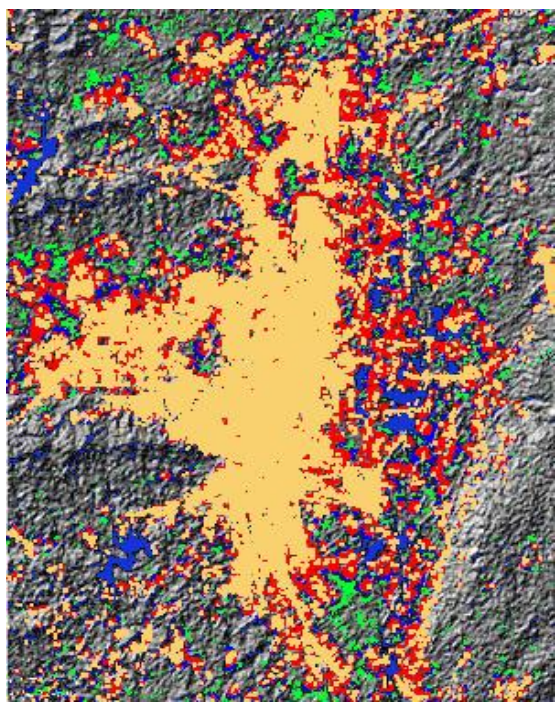

a

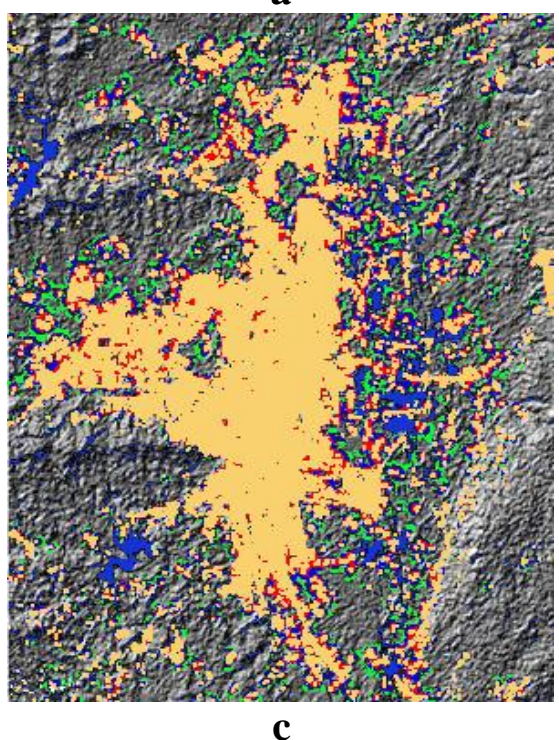

c

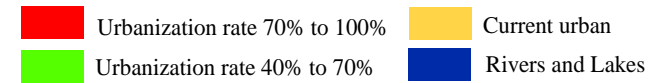

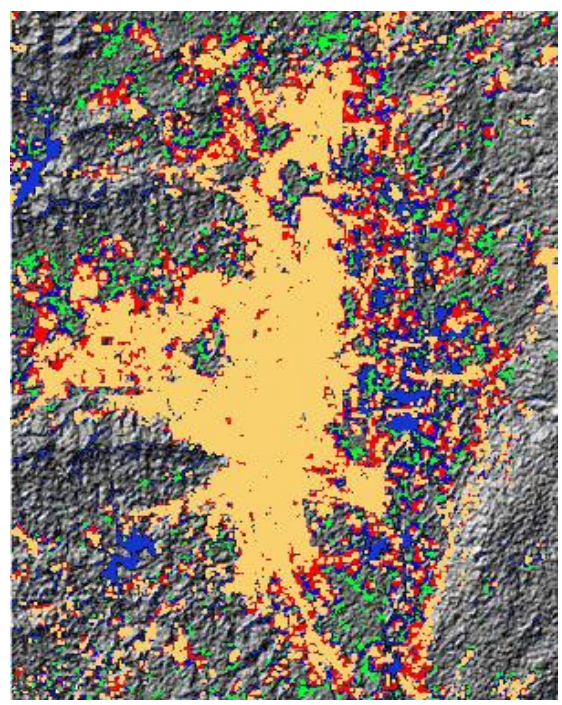

b

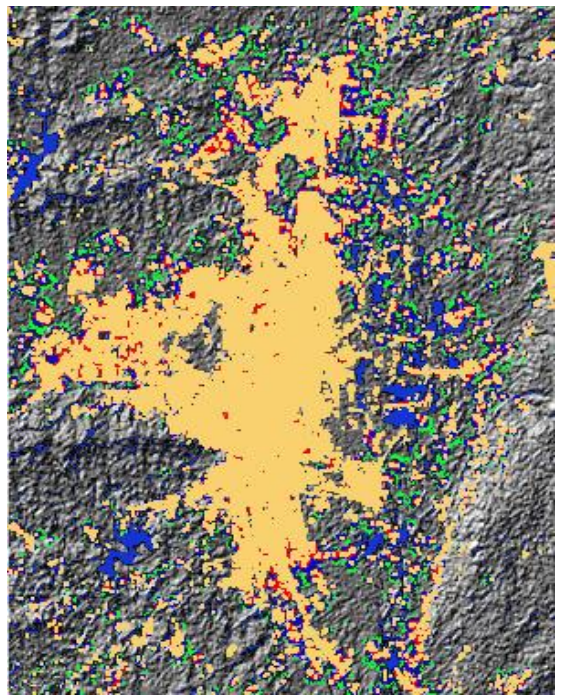

d

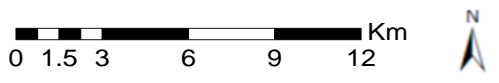

Figure 5. Urban expansion prediction of scenario 1-4. a Scenario 1, b scenario 2, $\boldsymbol{c}$ scenario 3, d scenario 4

Figure 5 ( $b$ and $c$ ) shows that the cities mainly extend to the north, the south and the west. The model which predicts the spatial pattern of urban development is basically consistent with the established urban planning, realizing the integrated urban structure system. The distribution of newly added city image element is obviously concentrated on the traffic road and the existing city periphery. It indicates that the road has played a 
major role in urban expansion (Rafiee et al., 2009; Dezhkam et al., 2014). However, in the planning-oriented scenario, there is still a large amount of ecological green spaces occupied in the process of urban expansion. This phenomenon is more prominent in the Qusheng Highway which lies in the east of the Daihe and Huangjiazhuang area. In the scenario of ecological development, the city carries out ecological construction at the same time and focuses on building the ecological cultural belt of the urban area with Mount Liaokuo and Nanpan River as the core. In this scenario, the city has realized the long-term ecological development plan of ecological landscape green corridor, which leads to the sustainable and harmonious development of the society, economy and culture. In this situation, through a series of the ecological landscape green corridor and other measures, the "one city, one river, one mountain" mode and the long-term blueprint of the scenic area have been achieved, which benefits the city's sustainable and coordinated development. Figure $5 d$ shows that in the ecological protection scenario, due to improved protection of forests and farmlands, rapid urban expansion has been effectively controlled and urban land growth rate has dropped to $1.23 \%$. But this restriction has obviously restricted the development of the city, which means by 2030 the area of the city would only increase by $39.33 \mathrm{~km}^{2}$. From the forecast results of four scenarios, it can be seen that the future cities mainly expand by marginal growth and road traction growth while the new urban center would hardly come into formation, and the impact of the slope is insignificant. The results are similar in other experiments (Dietzel and Clarke, 2007; Al-Shalabi et al., 2013). The inclusion of the exclusion layer can better guide the city development according to the established urban planning, so as to avoid the disordered urban development and the destruction of ecological green space. The four kinds of forecast scenarios can well reflect the predefined planning policy (Aerts et al., 2003; Jantz et al., 2004).

\section{The comparison of prediction results in four scenarios}

From 1993 to 2030, the urban land of the study area has always been increasing. The urban land growth rate remains at above $3 \%$. This phenomenon can be identified from Figure $6(a$ and $b)$ indicates that the study area has maintained a rapid development since 1993. The growth rate of the urban area increased first and then decreased in the period of 2000-2015, which indicates that the study area was at a time of rapid development before 2009, and the urban land increase rate was flat after 2009. However, according to forecast results, all the four kinds of scenarios present the growth tendency of the urban area.

According to the UESI (Fig. 6c), UESI has been more than 3.3 since 1993 and presented a growing trend. During the rapid expansion period of 1993-2009, the expansion rate slowed from 2009 to 2015 with the 2015 UESI being 6.34, and the city was in the middle-speed expansion stage (Wang et al., 2016). In the four scenarios, the UESI was gradually decreasing with the increase of urban ecological protection intensity. In the natural development scenario, UESI is as high as 8.37 in 2015-2030, much higher than UESI of the historical period; the city will be at a rapid growth rate of annual $8.37 \mathrm{~km}^{2}$. In the planning-oriented scenario, the city basically maintains the existing urban expansion speed and it is in the middle-speed expansion stage. In this scenario, UESI and the previous stage are quite. In the ecological development scenario, the city is at a low-speed expansion period, and the expansion speed drops slightly (AlSharif, 2014). In the ecological protection scenario, the UESI is only 2.62, the urban expansion is at the low-speed expansion stage, the growth rate declines to $2.62 \mathrm{~km}^{2}$ 
every year, and the urban expansion is obviously reduced compared with the historical periods.

According to Figure $6 d$, the UEII has been more than $3.4 \%$ since 1993; during 19932009, the UEII reached 4.9\%. However, it dropped to 3.6\% during 2009-2015. This is mainly because the government has made a local adjustment to the urban master plan, which restricts the construction and development of some ecological protection areas. In the four scenarios, the UEII gradually decreases with the increase of urban ecological protection intensity. In the natural development scenario, UEII is basically flat compared with the previous period from 2015 to 2030, the city will continue to maintain the strength of the strong expansion of urban development (Wang, 2016; Salvati et al., 2014). In planning-oriented scenarios and ecological development scenarios, the future expansion intensity of the city will be slightly lower than that of the previous period, but the UEII still maintain $2.3 \%$ to continue the development of the city. In the ecological protection scenario, the UEII descends to $1.23 \%$, which is far below the level of the recorded extended intensity $\mathrm{o}$ and the future expansion of the city will be obviously restricted.

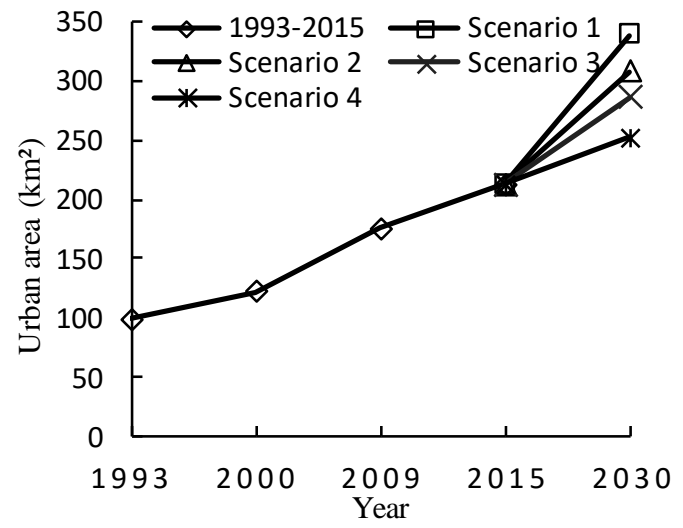

a

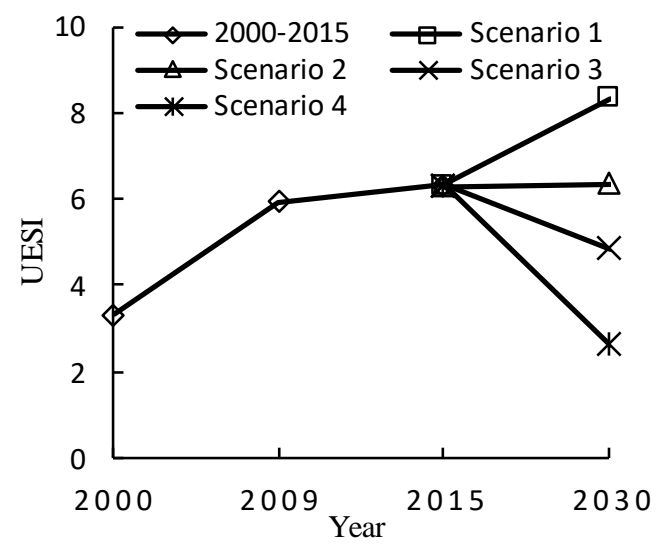

c

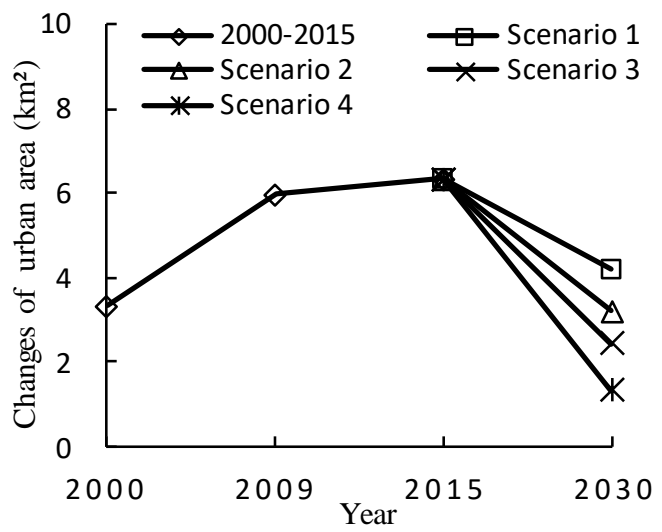

b

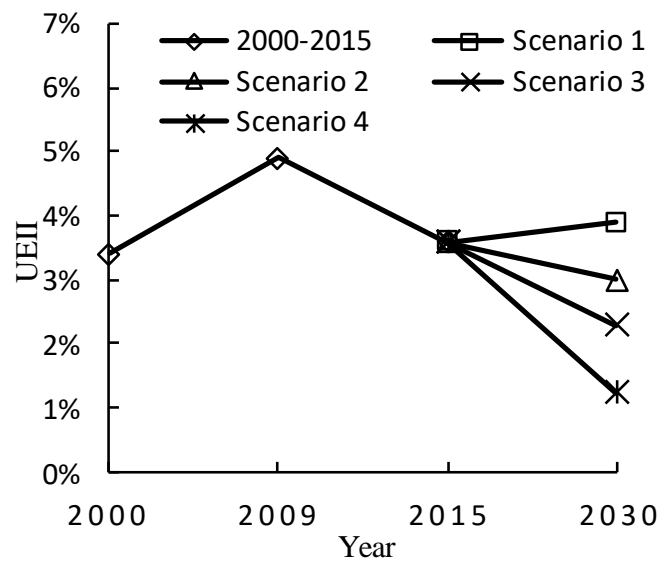

d

Figure 6. The statistics of urban area changes in different scenario. Changes in a total urban area, $\boldsymbol{b}$ urban area in each period, $\boldsymbol{c}$ urban expansion speed index and $\boldsymbol{d}$ urban expansion intensity index 
In order to choose the best forecast scenario, the predicted results of four scenarios were compared with the Urban Planning Project of 2030 (CAUPD and QCPB, 2016). We found that the predicted results of the ecological development scenarios were in accordance with the urban development requirements, especially in the urban spatial distribution. To prove this assumption, we extracted the urban land area data through the remote sensing image, with the image preprocessing and classification method being the same as other years'. The urban land of the research area is $225.5 \mathrm{~km}^{2}$ in 2018 . It can be seen from Figure $7 a$ that the urban area is closest to the result of the ecological development scenario. During this period, the urban area increased $12.23 \mathrm{~km}^{2}$, which exceeded the results of the four scenarios (Fig. 7b).

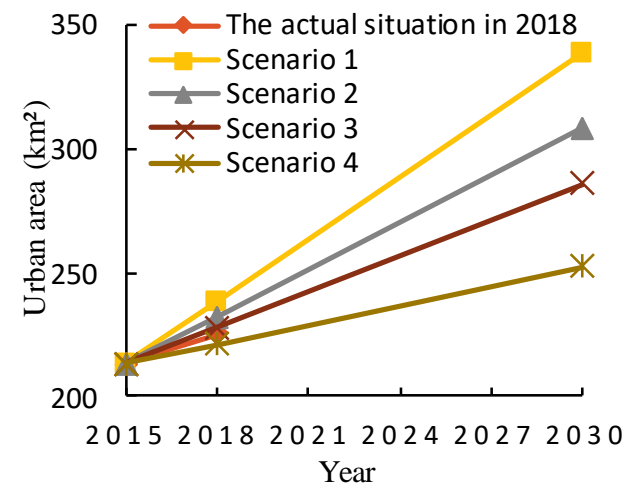

a

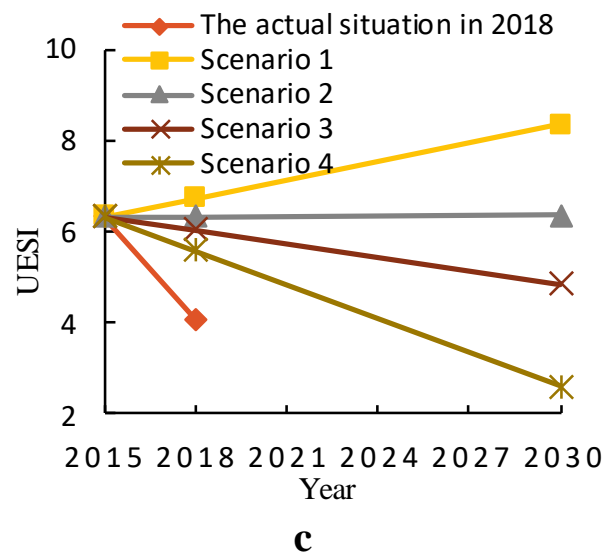

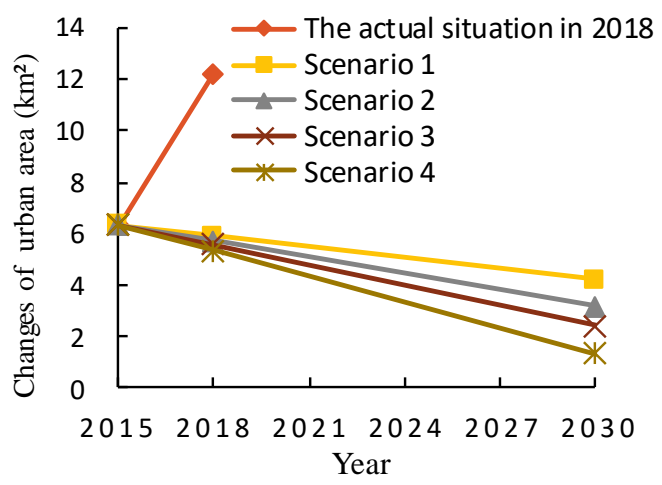

$\mathbf{b}$

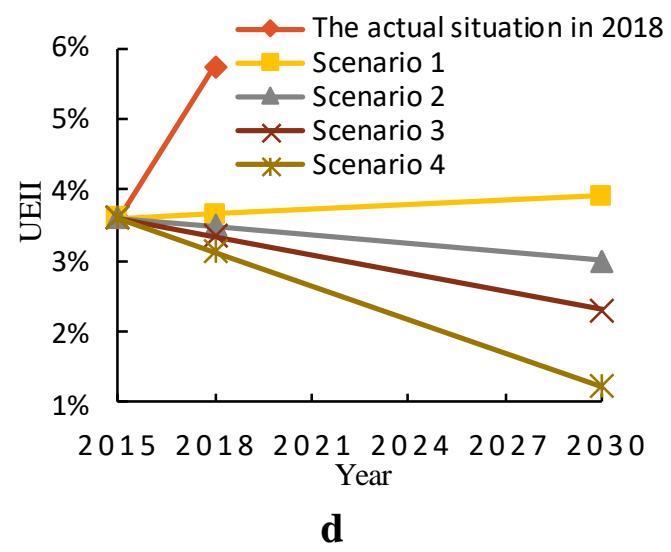

Figure 7. The comparison between the actual situation of research area and four scenarios. Comparison of $\boldsymbol{a}$ total urban area, $\boldsymbol{b}$ urban area in each period, $\boldsymbol{c}$ USEI and $\boldsymbol{d}$ UEII

The speed of urban expansion is limited to 4.07 (Fig. 7c), which is below the average velocity level of four scenarios (The average of four scenarios is 6.18). However, the urban expansion strength reached 5.3, which is much higher than the four scenarios predicted results (Fig. 7d). We speculate that because the government has strengthened the protection of ecological green space, the urban construction transfer from the blind expansion to high-quality development, and the rapid urbanization process was restricted. Therefore, from the perspective of the whole city, the speed of urban expansion has decreased. However, a large number of construction activities have 
occurred in some local areas of the city, which mainly occur in the fringe of urban settlements in the eastern part of the city; for example, people build large numbers of new houses and occupy farmland for commercial activities. These human activities explain why the growth of UESI slowed down but the UEII increased in the process of urban expansion.

\section{Conclusion}

This investigation integrates GIS, RS and SLEUTH model to simulate and predict the urban spatial expansion of the typical Chinese Nationally Designated Garden City (Qujing), and to explore the urban expansion trend under different ecological green space protection. Comparing the urban evolution laws in different scenarios, the results show that the SLEUTH model excels with a higher spatial matching degree with historical data, which enjoys better applicability and portability. The model can be used in Nationally Designated Garden Cities with dense vegetation and it can provide a reference for the sustainable development and urban planning of Nationally Designated Garden Cities in China. Under the protection intensity of different ecological green space, the urban area is obviously increased in four scenarios, and the other land types are occupied. This result indicates that the increase of urban land use is affecting the future space use pattern. By increasing the protection intensity of the ecological land around the city, the urban spatial expansion will be obviously restricted. It is mainly manifested by the decrease of UESI and UEII. Comparing the results of different scenarios, it is found that the future cities will spread around the present urban area in the natural development scenario. In the other three scenarios, the trend of urban expansion is expanding to the north, the south and the west, and would ultimately achieve the spatial integration of the Qiling and Zhanyi District, which is consistent with the requirements of urban master planning. Comparing with four scenarios, we found that the urban development trend predicted by the ecological development scenario is more similar to the urban planning, and this conclusion is confirmed by the 2018 distribution of urban areas. In the ecological development scenario, the urban ecological land has been effectively protected and the development of the city has not been affected, which is beneficial to the sustainable development of the city and the protection of the ecological environment. The ecological development scenario can minimize the impact on the urban ecological environment by increasing the protection of natural environment, controlling the development intensity and clarifying the direction of urban development. It is beneficial to the sustainable development of the city and the protection of the ecological environment.

We propose to use the SLEUTH model to reflect the spatial and temporal characteristics of urban expansion, and forecast urban expansion from both macroscopic and medium perspective (Silva and Clarke, 2005; Watkiss, 2008). In this case, the main factors affecting urban expansion, such as road, topography, lake and river are integrated into the urban expansion process. In this way, the results are more in accordance with the actual urban change. At the same time, the temporal resolution and spatial resolution of the image data will have certain influences on the prediction result of the model (Xiang and Clarke, 2003; Al-Shalabi et al., 2013; Chaudhuri and Clarke, 2014). This study selects four periods of city-wide data to test, and each designed period interval is between 6 to 9 years and the image space resolution is $30 \mathrm{~m}$. The application of higher resolution remote sensing imagery and increased urban base period data 
would help to improve the accuracy of urban expansion simulations. In addition, the setting of the exclusion layer is the key link that directly affects the prediction results (Aerts et al., 2003; Clarke et al., 1997). How to embed the factors suitable for population, greening coverage, built-up area greening, per capita public green area based on SLEUTH model, and how to comprehensively consider the influence of various factors in the process of urban expansion will be the focus of the next research.

Acknowledgements. The authors gratefully acknowledge funding from National Natural Science Foundation of China (No. 41101343), Yunnan Provincial Development and Reform Commission 2013 Yunnan High-tech industry development project plan, Chinese Academy of Sciences Computer Network Information Centre provides Landsat image and DEM data.

\section{REFERENCES}

[1] Aerts, J. C. J. H., Clarke, K. C., Keuper, A. D. (2003): Testing popular visualization techniques for representing model uncertainty. - American Cartographer 30(3): 249-261.

[2] Al-Shalabi, M., Billa, L., Pradhan, B. et al. (2013): Modelling urban growth evolution and land-use changes using GIS based cellular automata and SLEUTH models: the case of Sana'a metropolitan city, Yemen. - Environmental Earth Sciences 70(1): 425-437.

[3] Al-Sharif, A. A. A., Pradhan, B., Shafri, H. Z. M. et al. (2014): Quantitative analysis of urban sprawl in Tripoli using Pearson's Chi-Square statistics and urban expansion intensity index. - IOP Conference Series: Earth and Environmental Science 20(1): 012006.

[4] Black, D., Henderson, V. (1999): A theory of urban growth. - Journal of Political Economy 107(2): 252-284.

[5] Boulos, J. (2016): Sustainable development of coastal cities-proposal of a modelling framework to achieve sustainable city-port connectivity. - Procedia Social and Behavioral Sciences 216: 974-985.

[6] CAUPD, QCPB. (2016): The Urban Master Planning of Dongguan from the Year 2016 to 2030. - Qujing City Planning Bureau (QCPB), Qujing, China.

[7] Chaudhuri, G., Clarke, K. C. (2014): Temporal accuracy in urban growth forecasting: a study using the SLEUTH model. - Transactions in GIS 18(2): 302-320.

[8] Clarke, K. C., Gaydos, L. J. (1998): Loose-coupling a cellular automaton model and GIS: long-term urban growth prediction for San Francisco and Washington/Baltimore. International Journal of Geographical Information Systems 12(7): 699-714.

[9] Clarke, K. C., Hoppen, S., Gaydos, L. J. (1997): A self-modifying cellular automaton model of historical urbanization in the San Francisco Bay area. - Environment and Planning B: Planning and Design 24(2): 247-261.

[10] Dezhkam, S., Amiri, B. J., Darvishsefat, A. A. et al. (2014): Simulating the urban growth dimensions and scenario prediction through sleuth model: a case study of Rasht County, Guilan, Iran. - Geojournal 79(5): 591-604.

[11] Dietzel, C., Clarke, K. C. (2004): Spatial differences in multi-resolution urban automata modeling. - Transactions in GIS 8(4): 479-492.

[12] Dietzel, C., Clarke, K. C. (2007): Toward optimal calibration of the SLEUTH Land use change model. - Transactions in GIS 11(1): 29-45.

[13] Ding, S. (2010): An analysis of the resource-environmental base of Qujing city in the process of Yunnan central urban agglomeration development. - Resources and Environment in the Yangtze Basin s2: 6-10.

[14] Feng, H. H., Xia, B., Xiao-Qing, W. U. et al. (2008): Study on Urban growth simulation of Dongguan City based on SLEUTH model. - Geography and Geo-Information Science 24(6): 76-79. 
[15] Feng, H. H., Liu, H. P., Ying, L. Ü. (2012): Scenario prediction and analysis of urban growth using SLEUTH model. - Pedosphere 22(2): 206-216.

[16] Hansen, A. J., Knight, R. L., Marzluff, J. M. et al. (2005): Effects of exurban development on biodiversity: Patterns, mechanisms, and research needs. - Ecological Applications 15(6): 1893-1905.

[17] Herold, M., Goldstein, N. C., Clarke, K. C. (2003): The spatiotemporal form of urban growth: measurement, analysis and modelling. - Remote Sensing of Environment 86(3): 286-302.

[18] Jantz, C. A., Goetz, S. J., Shelley, M. K. (2004): Using the SLEUTH urban growth model to simulate the impacts of future policy scenarios on urban land use in the BaltimoreWashington metropolitan area. - Environment \& Planning B Planning \& Design 31(2): 251-271.

[19] Laura, M., Norman, D., Guertin, P., Feller, M. (2008): A coupled model approach to reduce nonpoint-source pollution resulting from predicted urban growth: A case study in the Ambos Nogales watershed. - Urban Geography 29(5): 496-516.

[20] Liu, X. P., Li, X., Shi, X. et al. Simulating land-use dynamics under planning policies by integrating artificial immune systems with cellular automata. - International Journal of Geographical Information Science 24(5): 783-802.

[21] López, T. M., Aide, T. M., Thomlinson, J. R. (2001): Urban expansion and the loss of prime agricultural lands in Puerto Rico. - Ambio 30(1): 49.

[22] Mc, C., Justin, H. (2013): Modeling of Urban Growth and Land Cover Change: An Implementation of the SLEUTH Model for San Marcos, Texas. - Texas State University, Texas, USA.

[23] Morf, H. (2011): The stochastic two-state cloud cover model STSCCM. - Solar Energy 85(5): 985-999.

[24] Peck, J. (2005): Struggling with the creative class. - International Journal of Urban \& Regional Research 29(4): 740-770.

[25] Pijanowski, B. C., Shellito, B., Pithadia, S. et al. (2002): Forecasting and assessing the impact of urban sprawl in coastal watersheds along eastern Lake Michigan. - Lakes \& Reservoirs Research \& Management 7(3): 271-285.

[26] Rafiee, R., Mahiny, A. S., Khorasani, N. et al. (2009): Simulating urban growth in Mashad City, Iran through the SLEUTH model (UGM). - Cities 26(1): 19-26.

[27] Roberts, D., Diederichs, N. (2016): Durban's Local Agenda 21 programme: Tackling sustainable development in a post-apartheid city. - Environment \& Urbanization 14(1): 189-201.

[28] Salvati, L., Ferrara, C., Ranalli, F. (2014): Changes at the fringe: Soil quality and environmental vulnerability during intense urban expansion. - Eurasian Soil Science 47(10): 1069-1075.

[29] Sangawongse, S., Sun, C. H., Tsai, B. W. (2005): Urban growth and land cover change in Chiang Mai and Taipei: Results from the sleuth model. - MODSIM 2005: International Congress on Modelling and Simulation: Advances and Applications for Management and Decision Making 10(3): 2622-2628.

[30] Silva, E. A., Clarke, K. C. (2002): Calibration of the SLEUTH urban growth model for Lisbon and Porto, Portugal. - Computers Environment \& Urban Systems 26(6): 525-552.

[31] Silva, E. A., Clarke, K. C. (2005): Complexity, emergence and cellular urban models: lessons learned from applying SLEUTH to two Portuguese metropolitan areas. European Planning Studies 13(1): 93-115.

[32] Solecki, W. D., Oliveri, C. (2004): Downscaling climate change scenarios in an urban land use change model. - Journal of Environmental Management 72(1-2): 105.

[33] Terry, L. D. (1995): Cooperative extension's urban expansion. - Administration \& Society 27(1): 54-81. 
[34] Wang, H., Chang, X., Zhang, A. et al. (2016): Space syntax expand intensity index and its applications to quantitative analysis of urban expansion. - Acta Geographica Sinica 71(8): 1302-1314.

[35] Watkiss, B. M. (2008): The SLEUTH urban growth model as forecasting and decisionmaking tool. - Retour Au Numéro 168(5): 5061-2.

[36] Xian, G., Crane, M. (2005): Assessments of urban growth in the Tampa Bay watershed using remote sensing data. - Remote Sensing of Environment 97(2): 203-215.

[37] Xiang, W. N., Clarke, K. C. (2003): The use of scenarios in land-use planning. Environment \& Planning B Planning \& Design 30(6): 885-909.

[38] Yea, C. D., Yong, K. Z. (2007): The simulation of urban growth applying SLEUTH Ca model to the Yilan delta in Taiwan. - Journal Alam Bina 9(1).

[39] Yeh, G. O., Li, X. (2001): A constrained CA model for the simulation and planning of sustainable urban forms by using GIS. - Environment \& Planning B: Planning \& Design 28(5): 733-753.

[40] Yuan, J. F., Huang, J., Zhang, R. et al. (2017): Evaluation and analysis of the climate Comfort degree of human settlements in Qujing urban area. - Journal of Yunnan University (Natural Sciences Edition) (S1): 77-82.

[41] Zhao, Y., Zhang, K., Peng, Y. et al. (2014): Scenario analysis of urban growth in Kunming based on geosimulation system. - Geographical Research 33(1): 119-131. 